\title{
Essential palatal tremor with hemifacial and vocal cord tremor
}

\author{
Akhila Kumar Panda, Suman Kushwaha, Manmeet Kaur
}

Department of Neurology, Institute of Human Behaviour \& Allied Sciences, Delhi, India

\section{Correspondence to} Dr Akhila Kumar Panda, drakhilapanda@gmail.com
To cite: Panda AK, Kushwaha S, Kaur M. BMJ Case Rep Published online: [please include Day Month Year] doi:10.1136/bcr-2013201327

\section{DESCRIPTION}

A 34-year-old man presented with voice tremor with rhythmic, high-frequency tremulousness movement of left face involving ala nasae, angle of mouth, eye brow, orbicularis oculi and frontalis muscles for 1 month prior to medical attention. The symptoms were static but made him distressed while in conversation with friends or clients. $\mathrm{He}$ did not have blepharospasm, hemifacial spasm or any cranial nerve deficit. He denied of ear click. His medical and family histories were unremarkable. Nervous system examinations showed rhythmic high-frequency tremor of soft palate with left hemifacial tremor (video 1). Video laryngoscope showed high-frequency bilateral vocal cord tremor (video 2). His brain MRI with fast imaging employing steady-state acquisition sequence was normal (figure 1). MR angiogram of neck and intracranial vessels and laboratory investigations were unremarkable. He responded well to clonazepam up to $4 \mathrm{mg} /$ day.

Palatal tremor refers to involuntary, segmental, spontaneous and rhythmic contraction of the soft palate. It is classified into symptomatic palatal tremor (SPT) and essential palatal tremor (EPT). SPT is usually associated with olivary pseudohypertrophy or focal lesions involving dentato-rubro-olivary pathway 'Guillain-Mollaret triangle'. ${ }^{12}$ The common aetiologies of SPT are stroke, tumour, trauma, abscess, arteriovenous malformations, ectatic arteries, and some metabolic and demyelinating illness. ${ }^{12}$ In SPT,

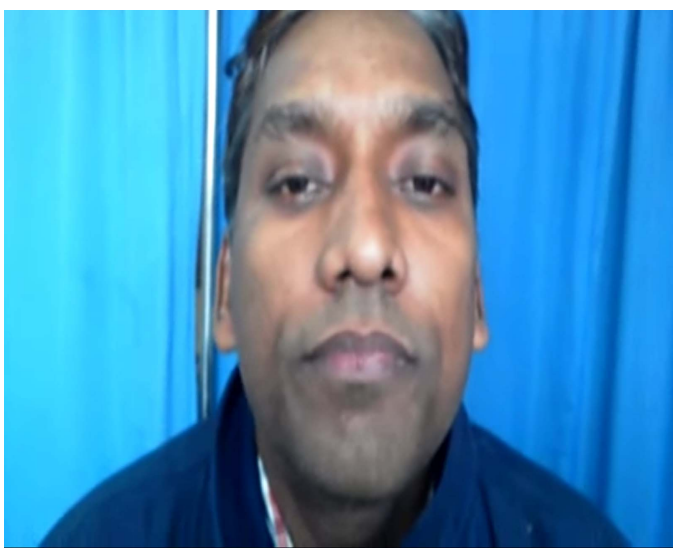

Video 1 Rhythmic high frequency tremor of soft palate with left hemi-face involving ala nasae, angle of mouth, eye brow, orbicularis oculi and frontalis muscles.

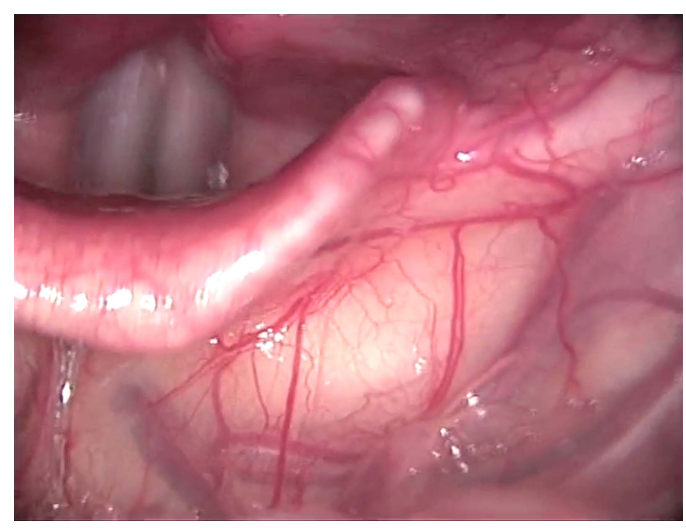

Video 2 Video laryngoscopy showing rhythmic high frequency bilateral vocal cord tremor.

tremor may involve facial, ocular and extremity muscles with absence of ear clicks. The palatal tremor usually persists during sleep unlike in EPT where it is variable. EPT does not have definable aetiology with younger age of presentation. It is associated with ear-clicking. ${ }^{2}$ Absence of extra palatal movement disorders as well as normal neuroimaging favours the diagnosis. ${ }^{2}$ Treatment is based on pharmacotherapy such as anticonvulsants (valproate, phenytoin, phenobarbital and lamotrigine), sedatives (clonazepam) and anticholinergic (trihexyphenydil) which have variable success. Injection with botulinum toxin $\mathrm{A}$ is effective and safe in EPT. ${ }^{3}$

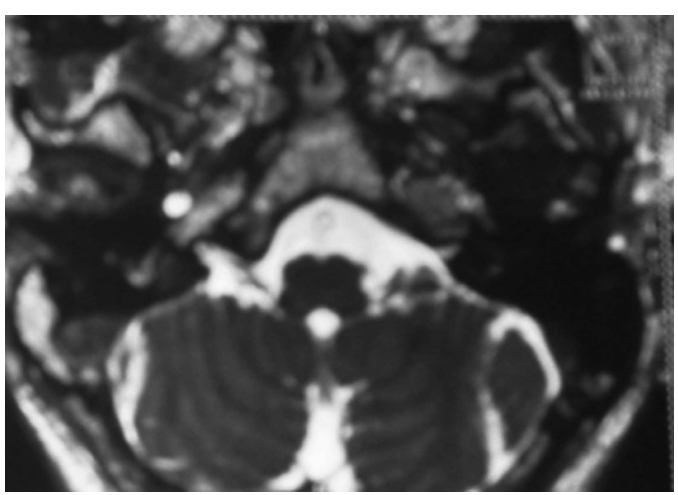

Figure 1 Axial sequence of brain MRI with fast imaging employing steady state acquisition sequence was normal. There was no olivary degeneration or hypertrophy. 


\section{Learning point}

- In our case, essential palatal tremor is associated with left hemifacial and vocal cord tremor which is quite rare in the current literatures.

- Ear clicks may be one of the important clinical findings which differentiates essential from symptomatic palatal tremors unlike the present case.

- Treatment of palatal tremor includes anticonvulsants, sedatives and anticholinergic with variable success. Injection botulinum toxin A therapy has been observed to be very useful in essential palatal tremor.
Contributors AKP was involved in the conception and design, interpretation of data and revising it critically for important intellectual content, and also gave final approval of the version published. SK and MK participated in the acquisition of data or analysis and interpretation of data, drafting of the manuscript and gave final approval of the version published.

Competing interests None.

Patient consent Obtained.

Provenance and peer review Not commissioned; externally peer reviewed.

\section{REFERENCES}

1 Deuschl G, Mischke G, Schenck E, et al. Symptomatic and essential rhythmic palatal myoclonus. Brain 1990;113:1645-72.

2 Zadikoff $C$, Lang AE, Klein C. The 'essentials' of essential palatal tremor: a reappraisal of the nosology. Brain 2006;129:832-40.

3 Penney SE, Bruce IA, Saeed SR. Botulinum toxin is effective and safe for palatal tremor: a report of five cases and a review of the literature. J Neurol 2006;253:857-60.

Copyright 2013 BMJ Publishing Group. All rights reserved. For permission to reuse any of this content visit http://group.bmj.com/group/rights-licensing/permissions.

BMJ Case Report Fellows may re-use this article for personal use and teaching without any further permission.

Become a Fellow of BMJ Case Reports today and you can:

- Submit as many cases as you like

- Enjoy fast sympathetic peer review and rapid publication of accepted articles

- Access all the published articles

- Re-use any of the published material for personal use and teaching without further permission

For information on Institutional Fellowships contact consortiasales@bmjgroup.com

Visit casereports.bmj.com for more articles like this and to become a Fellow 